\title{
How salty is your sambo? - a pilot study to assess the feasibility of collecting out-of-home sources of salt in Ireland
}

In Ireland, it is recommended that the population should reduce their salt intake to $6 \mathrm{~g}$ per/day ${ }^{(1)}$. Processed and out-of-home $(\mathrm{OOH})$ foods are account for approximately $70 \%$ of an individual's salt intake ${ }^{(2)}$. While the Food Safety Authority of Ireland (FSAI) has extensive data monitoring the salt reduction efforts of the food industry relating to processed foods ${ }^{(1)}$, there is a dearth of information regarding $\mathrm{OOH}$ salt sources in Ireland. The aims of this study are to: ${ }^{(1)}$. assess the feasibility in collecting $\mathrm{OOH}$ sources of salt with respect to lunchtime food options and ${ }^{(2)}$. investigate the concentrations of sodium and potassium of a sample of pre-packaged sandwiches on the Irish market and assess their healthiness using the Traffic Light System ${ }^{(3)}$.

Pre-packaged sandwiches were sampled from Dublin supermarkets and convenience stores in August 2020. Two popular varieties were collected - Bacon, Lettuce and Tomato (BLT) and Ham \& Cheese varieties. Samples were sent to public analyst laboratory in Galway for analysis of sodium and potassium content per $100 \mathrm{~g}$, using atomic emission spectrophotometry. Sodium values were multiplied by 2.54 to determine the salt content $(\mathrm{g})$ of samples(1). Frequency statistics and independent $\mathrm{t}$-tests were conducted to analyse the data using IBM SPSS (version 25). Due to small sample size, non-parametric tests were also performed. Results are presented as median values (minimum and maximum).

A total of n20 pre-packaged sandwiches were collected: BLT (n8) and Ham \& Cheese (n12). For sodium, BLT and Ham \& Cheese varieties were found to have $0.47 \mathrm{~g}(0.43-0.59)$ and $0.55 \mathrm{~g}(0.40-0.63)$ per $100 \mathrm{~g}$ food product respectively. In terms of potassium, BLT and Ham \& Cheese varieties had $0.21 \mathrm{~g}(0.13-0.27)$ and $0.18 \mathrm{~g}(0.12-0.24)$ per $100 \mathrm{~g}$ food respectively. There were no significant differences between the two categories of sandwiches in terms of sodium or potassium. BLT and Ham \& Cheese varieties were found to

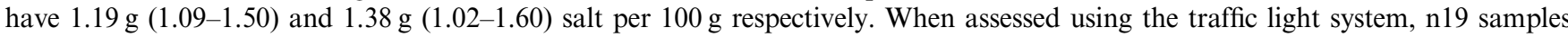
were classified within the orange category $(0.3-1.5 \mathrm{~g}$ per $100 \mathrm{~g})$ with one sample within the red category $(>1.5 \mathrm{~g}$ per $100 \mathrm{~g})$ for salt.

This work demonstrates the results of a pilot study to assess the feasibility of collecting one type of OOH data for salt monitoring purposes. In terms of sodium and potassium, there is no difference in the health impact of eating either type of sandwich. Nearly all samples $(95 \%)$ were within the orange category and one sample in the red category in terms of the traffic light system. This suggests that reformulation efforts in this food category are needed to contribute to reducing population salt intakes. Future FSAI work will involve continuing to monitor salt reformulation practices.

\section{References}

1. Food Safety Authority of Ireland (2019) [Available at: https://www.fsai.ie/uploadedFiles/Science_and_Health/Salt_and_Health/Salt_Surveys_2003_ onwards.pdf].

2. Safefood (2021) [Available at: https://www.safefood.net/healthy-eating/salt].

3. Brownell KD \& Koplan JP (2011) N Engl J Med 364, 2373-2375. 